Original Article

Artigo Original

Rosana Prado-Oliveira ${ }^{1}$

|lza Lazarini Marques ${ }^{1}$

Luiz de Souza ${ }^{2}$

Telma Vidoto de Souza-Brosco ${ }^{1}$

Jeniffer de Cássia Rillo Dutka ${ }^{3}$

Keywords

Robin Sequence

Cleft Palate

Hypernasality

Nasometry

Palatoplasty

Descritores

Sequência de Robin

Fissura Palatina

Hipernasalidade

Nasometria

Palatoplastia

Correspondence address:

Jeniffer de Cássia Rillo Dutka

Hospital de Reabilitação de Anomalias Craniofaciais, Universidade de São Paulo Rua Silvio Marchioni, 3-20, Bauru (SP), Brazil, CEP: 17043-900.

E-mail: jdutka@usp.br

Received: 06/24/2014

\section{Assessment of speech nasality in children \\ with Robin Sequence}

\author{
Avaliação da nasalidade de fala em crianças \\ com Sequência de Robin
}

\begin{abstract}
Purpose: To report the outcomes of primary palatoplasty in Robin Sequence (RS); to verify the relationship between modalities of assessment of nasality; to compare nasality between techniques at palatoplasty. Methods: This study involved the identification of hypernasality in four modalities: live assessment with 4-point scale; live assessment with cul-de-sac test; multiple listeners' ratings of recorded phrase; nasometric assessment. Live ratings of speech nasality and nasalance scores were retrieved from charts, while a recorded phrase was rated by listeners for occurrence of hypernasality. Agreement between the modalities was established as well as association between nasality, nasal turbulence and age at surgery and at assessment. Fisher's exact test was used to compare findings between surgical techniques. Results: Agreement between nasalance, live assessment with 4-point scale, live assessment with cul-de-sac, and multiple listeners' ratings of recorded samples ranged between reasonable (0.32) and perfect (1.00). Percentage occurrence of hypernasality varied largely between assessment modalities. Mean occurrence of hypernasality was lower for the group submitted to Furlow technique (26\%) than the group that received von Langenbeck technique (53\%). Only findings obtained live were statistically significant (scale: $\mathrm{p}=0.012 ;$ cul-de-sac: $\mathrm{p}<0.001$ ). Listeners identified nasal turbulence for $22(32 \%)$ samples out of the 69 recordings, and an association was found between hypernasality and nasal turbulence. Conclusion: Lower occurrence of hypernasality was identified for patients with RS in Furlow group. Identification of hypernasality varied largely among the four assessment modalities.
\end{abstract}

\section{RESUMO}

Objetivo: Reportar os resultados da palatoplastia primária na Sequência de Robin (SR); verificar a relação entre modalidades de avaliação da nasalidade; comparar nasalidade entre técnicas na palatoplastia. Métodos: Este estudo envolveu a identificação da hipernasalidade em quatro modalidades: avaliação ao vivo com escala de quatro pontos; avaliação ao vivo com teste cul-de-sac; julgamento de gravações por juízes e avaliação nasométrica. Julgamentos ao vivo da nasalidade e escores de nasalância foram obtidos em prontuários, enquanto uma frase gravada foi julgada por juízes para ocorrência de nasalidade. Concordância entre as quatro modalidades foi estabelecida assim como associação entre nasalidade, turbulência nasal e idades na cirurgia e na avaliação. Teste exato de Fisher foi usado para comparar achados entre as técnicas cirúrgicas. Resultados: A concordância entre nasalância, avaliação ao vivo com escala de quatro pontos e com teste $c u l$-de-sac e julgamentos de gravações por juízes variou entre razoável $(0,32)$ e perfeita $(1,00)$. Porcentagem de ocorrência de hipernasalidade variou muito entre as diferentes modalidades. Ocorrência média de hipernsalidade no grupo operado com técnica de Furlow foi menor (26\%) do que no grupo que recebeu a técnica de von Langenbeck (53\%). Somente os resultados avaliados ao vivo foram estatisticamente significantes (escala: $\mathrm{p}=0,012 ;$ cul-de-sac: $\mathrm{p}<0,001)$. Juízes ouviram turbulência nasal em 22 (32\%) das 69 gravações e uma associação entre hipernasalidade e turbulência nasal foi encontrada. Conclusão: Ocorrência de hipernasalidade foi menor para os pacientes com SR que receberam a técnica de Furlow. Identificação da hipernasalidade variou grandemente entre as quatro modalidades de avaliação.

Study carried out at the Hospital for Rehabilitation of Craniofacial Anomalies, Universidade de São Paulo USP - Bauru (SP), Brazil.

(1) Hospital of Rehabilitation for Craniofacial Anomalies, Universidade de São Paulo - USP - Bauru (SP), Brazil. (2) School of Medicine of Ribeirão Preto, Universidade de São Paulo - USP - Ribeirão Preto (SP), Brazil.

(3) Graduate Program in Rehabilitation Sciences, Hospital for Rehabilitation of Craniofacial Anomalies, Universidade de São Paulo - USP - Bauru (SP); Undergraduate Program in Speech-Language and Audiology, School of Dentistry of Bauru, Universidade de São Paulo - USP - Bauru (SP), Brazil.

Conflict of interests: nothing to declare. 


\section{INTRODUCTION}

Besides micrognathia and glossoptosis, children with Robin Sequence (RS) can also present with a wide U-shapped cleft palate ${ }^{(1)}$. Early repair of the cleft is recommended to promote adequate velopharyngeal function and to prevent communication disorders. Primary palatoplasty in babies with RS, however, has to be timed to the management of upper respiratory obstruction and feeding difficulties, and may be delayed due to the severity of respiratory symptoms and the child's response to the procedure chosen for management of respiratory and feeding conditions present at birth ${ }^{(2,3)}$. Once respiratory distress and feeding difficulties are controlled, teams usually proceed with repair of the cleft palate. Several surgical procedures have been described for primary repair of cleft palate and the literature shows particular interest to the Furlow double opposing z-plasty since it proposes to create a functional palatal muscle sling with increased velar length ${ }^{(4)}$. Even though the extra velar length may certainly improve the chances of adequate velopharyngeal functioning, some authors reported that this technique is more successful for patients with narrower clefts and may be associated to higher risk for palatal fistula ${ }^{(4)}$.

Even though cleft palate is a common finding in babies with $\mathrm{RS}$, the literature is limited regarding speech outcome for primary palatoplasty, particularly for children with non-syndromic $\mathrm{RS}^{(5-14)}$. While some authors included children with RS in their studies, they ${ }^{(5)}$ did not report speech findings specific for the participants with the Sequence. One study ${ }^{(6)}$ compared a group of 26 patients with RS to 135 patients without the Sequence and reported no significant differences regarding the need for surgical management of Velopharyngeal Insufficiency (VPI) between the groups. The authors ${ }^{(6)}$, however, found a significant difference regarding the presence of nasal air escape, which occurred in $36 \%$ of patients with RS compared to $10 \%$ in patients without RS. Another study ${ }^{(7)}$ found lower occurrence of normal speech in patients with RS and reported that 53\% of their 30 patients with the Sequence needed surgical management of VPI after primary palatoplasty. Some researchers ${ }^{(8)}$ reported speech outcome after palatoplasty for 54 patients: 21 with cleft lip and palate and 33 with cleft palate only. In the group of patients with cleft palate only, 14 were identified with RS. While surgical management of VPI was indicated for $26 \%$ of the patients with cleft palate only, it was recommended to $36 \%$ of patients with the $\mathrm{RS}^{(8)}$, a finding similar to that reported in another article ${ }^{(9)}$ but higher than the findings published by other group of investigators ${ }^{(10)}$. When comparing patients with syndromic and non-syndromic RS, one article ${ }^{(1)}$ indicated no significant difference regarding incidence of VPI; another article ${ }^{(12)}$ reported a significantly greater rate of VPI for the population with syndromic RS. A team of researchers ${ }^{(13)}$ studied a group of 39 children with RS and a severe neonatal disorders including respiratory and feeding difficulties. According to the authors ${ }^{(13)}, 69 \%$ of their patients presented with persistent hypernasality at 6 years of age. Finally, another group of investigators ${ }^{(14)}$ reported that about $47 \%$ of their patients with non-syndromic RS demonstrated signs of velopharyngeal dysfunction compared to $28 \%$ of patients with non-syndromic cleft of the palate only.
These studies show not only a wide range of speech outcome but also different methodological approaches to document speech outcome, which makes comparisons a difficult task. To further contribute with information regarding speech nasality in children with RS and operated cleft palate, this study was designed to contribute with data regarding occurrence of hypernasality after primary palatoplasty in children with RS. The purposes of this study were: to report the outcome of primary repair of cleft palate in children with RS; to verify the relationship between different modalities of assessment of nasality; to compare nasality outcomes between techniques for primary palatoplasty.

\section{METHODS}

This study was approved by the Human Research Ethics Committee at the Hospital for Rehabilitation of Craniofacial Anomalies, Universidade de São Paulo, Bauru, Brazil. A retrospective analysis of records of patients with isolated RS was conducted followed by the retrieval of nasalance scores and speech recordings. The 69 available recordings were edited and presented to listeners for ratings of speech nasality.

\section{Participants}

A list of patients with RS operated by the same surgeon was obtained at the institution where the study was conducted, and only patients with speech recordings and at least one live auditory-perceptual evaluation of speech reported in the patients' charts were studied. A total of 69 speech recordings were available for patients with RS with operated cleft palate, and the charts for all these patients were retrieved and studied. Diagnosis of RS was done by the Genetics team with collaboration of a pediatrician experienced with the management of patients with the Sequence, as routine protocol at the research institution.

\section{Live ratings of speech nasality}

Retrospective analysis of the participant's records involved the identification of technique and age at primary palatoplasty as well as indications of hypernasality occurrence. Hypernasality was assessed live and reported in patients' records by a single Speech-Language Pathologist (SLP) with more than 20 years experience with assessment of speech of children with cleft lip and palate (CLP). For the live ratings of nasality, the SLP elicited a short sample of connected speech during a brief conversation and classified speech nasality in one of four possible levels (4-point scale) to rate hypernasality ( $1=$ absent hypernasality, $2=$ mild hypernasality, $3=$ moderate hypernasality, and $4=$ se vere hypernasality). At the same visit, the SLP also established an index of the consistency of hypernasality using a cul-de-sac test during the production of ten oral words. Cul-de-sac scores were retrieved from patients' charts and ranged between zero to ten, in which zero indicated no perceptible difference in nasality while ten indicated a perceptible shift occurring on each tested word, when comparing productions with nares closed to those with nares open, as described in the literature ${ }^{(4)}$. 


\section{Listeners' ratings of recorded phrase}

Audio recordings from 69 participants during the production of one oral phrase (/o bebe babow/) were captured during nasometric assessment, using an AKG C420 microphone (condensed, unidirectional) attached to the nasometer separator plate. This microphone was connected to a Sound Blaster Audigy2 board installed in a computer. The audio samples were saved as ".wav" files using the Sony Sound Forge (version 8.0), and later were edited for listeners' ratings. The audio samples of 14 participants $(20 \%)$ were randomly repeated in the material for measures of intrajudge reliability. A total of 83 audio samples $(69+14)$ were played to three listeners, independently, using a personal computer and ear phones. Listeners were allowed to adjust the audio output to an acceptable sound level for adequate ratings of the material and could repeat the samples until reaching a decision regarding the presence or absence of hypernasal speech.

Three SLPs with more than five years of experience with daily evaluation of speech errors related to CLP rated all samples. Listeners' preparation was done individually and immediately prior to the ratings and involved the presentation of the phrase lo bebe baboul, once produced with hypernasality and once produced without hypernasality. Listeners were asked if they could hear the difference between the two productions and, since they agreed, they were asked if they could indicate which phrase was produced with hypernasality. The three listeners had no difficulty identifying presence/absence of hypernasality in the trial samples and were told that their task was to rate 83 samples, indicating if they heard the presence or the absence of hypernasality for each sample. They were given a form to record their findings, which included 83 repetitions of the phrase, numbered from one to 83 , each with two choices regarding hypernasality (present or absent), followed by a space to be used in case the listeners noted speech deviations other then hypernasality.

\section{Nasometric assessment}

Nasalance scores for the phrase of interest were retrieved from all 69 patients' charts. While nasometry is usually conducted with longer passages, the use of syllable repetition and words has been standardized with the Snap Test, and the use of short phrase has been suggested to be valid in the literature $^{(15,16)}$. At the research site, short phrases are frequently used and have been normatized for Brazilian Portuguese speakers ${ }^{(16)}$. Since the phrase /o bebe babou/ is correctly repeated by most children as young as 4 years of age, nasalance scores obtained during production of the short phrase were studied in this investigation. That is, the samples for multiple listeners' ratings of speech nasality and for nasalance scores were recorded simultaneously during the production of one short phrase with five syllables.

The nasalance scores retrieved for this study were obtained by a single SLP, experienced with nasometry, using Kay Elemetrics' Nasometer (Model 6220-2). Calibration, data recording and calculation of nasalance scores were done according to the procedures described in the Nasometer's Manual. As routine, at the research site, the participants practiced the production of the phrase once requested by the examiner. The examiner observed the accurary of the production, making sure that compensatory articulation was not used. The productions were captured by the Nasometer and simultaneously by an AKG microphone attached to the separator plate. Another examiner monitored the speech productions and assured a stable positioning of the Nasometer's separator plate. Interpretation of the nasalance values was done using the cut-off value of $27 \%$ suggested for Brazilian Portuguese language by Trindade et al. ${ }^{(16)}$.

\section{Data interpretation and analysis}

Patients were grouped according to the two techniques used at primary palatoplasty (F: Furlow, VL: von Langenbeck). Percentage of hypernasal speech occurrence was established for each of the four different modalities for assessment of nasality:

1. hypernasality rated live with 4-point scale;

2. hypernasality rated live with cul-de-sac test;

3. listeners' ratings of recorded samples; and

4. nasalance scores.

For comparison purposes, all measurements were simplified into a binary system indicative of hypernasality presence or absence. For the 4-point scale, the ratings of 2 (mild hypernasality), 3 (moderate hypernasality) and 4 (severe hypernasality) were group as indicative of hypernasality presence. For the $c u l-d e-s a c$ test, the indexes of 3 or more were interpreted as indicative of hypernasality presence and indexes of 0,1 , and 2 were interpreted as indicative of hypernasality absence. Nasalance scores above $27 \%$ were interpreted as indicative of hypernasality presence, while nasalance lower than $27 \%$ was indicative of absence. Listers rated the recorded phrase using the binary system, indicating hypernasality presence or absence.

Inter and intrajudge agreements during listeners' ratings of the recorded phrase were established using Kappa statistic. The relationship between the different modalities of nasality assessment was also established using Kappa statistic. A point estimate of the Odds Ratio of hypernasality presence was identified for each modality of nasality assessment. Multiple regression was used to investigate the association between nasality, age at primary repair, age at speech assessment and nasal turbulence. Fisher's exact test was used to compare findings among techniques at primary palatoplasty.

\section{RESULTS}

Within the group of 69 patients studied, 33 received the F-procedure (48\%) and 36 received the modified VLprocedure $(52 \%)$. Gender distribution was similar among the groups with $58 \%$ females and $42 \%$ males. Mean age at time of primary palatoplasty was 20 months (m) for the VL-group (range: $12-44 \mathrm{~m}$ ), and $17 \mathrm{~m}$ for the F-group (range: $12-35 \mathrm{~m}$ ). Mean age at time of speech assessments was $69 \mathrm{~m}$ for the VL-group (range: 49-120m), and $89 \mathrm{~m}$ for the F-group (range: $68-114 \mathrm{~m}$ ). 


\section{Agreement among listeners' during ratings of recorded speech}

Three experienced SLPs rated the 69 samples available for this study. A single score regarding the presence or absence of hypernasality was identified for each sample using agreement among the majority of the listeners as the criteria for establishing a single rating for each recording. That is, a speaker was considered to present hypernasality if at least two out of three listeners identified hypernasal speech. The SLPs agreed 100\% (three out of three listeners) regarding the nasality ratings for $74 \%$ of the samples rated $(n=51)$. For the remaining 18 samples (26\%), nasality ratings were based on agreement among two out of three listeners. Overall Kappa score for the group indicated moderate interjudge agreement between listeners (0.53), ranging between moderate (0.43) and substantial (0.67). Substantial intrajuge agreement was found for the group (0.64), with individual listener's agreement varying from reasonable (0.29), for one listener, to substantial (0.63) and perfect (1.00) for the other two listeners, respectively. During ratings, the listeners identified presence of nasal turbulence in $22(32 \%)$ recordings. Nasal turbulence was treated as a confounding variable and the agreement between listeners was also established for the 47 samples without nasal turbulence. Kappa score for the group without nasal turbulence indicated substantial agreement (0.74), ranging between 0.67 and 0.78 among the listeners.

\section{Nasality outcome}

Table 1 presents percentage occurrence of hypernasality as identified with the four modalities of assessment. An overall lower occurrence of hypernasality was observed for the F-group when compared to the VL-group. Nasometric findings revealed that $54 \%$ of the children in the F-group and $74 \%$ in the VL-group presented with scores indicative of hypernasality presence. Percentage occurrence of hypernasality for the four modalities varied between 9 and $54 \%$ for the F-group and between 33 and $74 \%$ for the VL-group. While comparing the difference between techniques, higher occurrence of hypernasality was observed for the VL-group in all modalities, with a difference ranging between 20 and 44\% (Table 2). When only samples without nasal turbulence were considered $(n=47)$, a lower occurrence of hypernasality was identified. Mean percentage occurrence of hypernasal speech was lower for all modalities when participants with nasal turbulence were not considered, varying between 17 and $50 \%$.

\section{Comparison between Furlow and Langenbeck groups}

Fisher's exact test revealed that nasality was significantly better for the group treated with the Furlow procedure when considering the results of the live 4-point scale $(\mathrm{p}=0.012)$ and live $c u l-d e-s a c$ test $(\mathrm{p}<0.001)$. Differences between nasality measures established by multiple listeners' ratings and nasalance scores were not significant (Table 1). Considering hypernasality absence as measure of surgical success, the point estimate of the Odds Ratio of presence of adequate speech was established for each assessment modality and is shown in Table 2. The estimated Odds Ratio for all modalities favored the Furlow procedure and was significant for the 4-point scale and for cul-de-sac test. Odds Ratio, for this study, was defined as the number of times the chances for normal nasality for the F-group corresponded to the chances in the VL-group. The 4-point scale measure suggested that the chances of a child with RS in F-group to have absence of

Table 1. Distribution of occurrence of hypernasality $(\%)$ for all children with Robin Sequence $(n=69)$, for children without nasal turbulence $(n=47)$ and for children distributed according to surgical technique at primary palatoplasty (Furlow or von Langenbeck), and the p-value indicating significant difference in hypernasality outcome between surgical techniques

\begin{tabular}{|c|c|c|c|c|c|}
\hline$\%$ hypernasality & $\begin{array}{l}\text { All children with RS } \\
(n=69)\end{array}$ & $\begin{array}{l}\text { No nasal turbulence } \\
(\mathrm{n}=47)\end{array}$ & $\begin{array}{l}\text { Furlow technique } \\
(\mathrm{n}=33)\end{array}$ & $\begin{array}{l}\text { Von Langenbeck } \\
\text { technique }(n=36)\end{array}$ & $p$-value \\
\hline 4-point scale & 37 & 26 & 21 & 53 & 0.012 \\
\hline Cul-de-sac & 31 & 26 & 9 & 53 & $<0.001$ \\
\hline Nasalance scores & 64 & 50 & 54 & 74 & Not significant \\
\hline
\end{tabular}

Caption: RS = Robin Sequence

Table 2. Percentual difference in nasality outcome, estimated Odds Ratio, and significance of difference between surgical techniques according to all four assessment modalities

\begin{tabular}{|c|c|c|c|c|c|c|}
\hline \multirow{2}{*}{ Modalities } & \multicolumn{3}{|c|}{ All samples $(n=69)$} & \multicolumn{3}{|c|}{ No nasal turbulence $(n=47)$} \\
\hline & Difference & Estimated Odds Ratio & $p$-value & Difference & Estimated Odds Ratio & $\mathrm{p}$-value \\
\hline Cul-de-sac & 44 & 11.2 & $<0.001^{*}$ & 36 & 8.5 & $0.008^{*}$ \\
\hline Nasometry & 20 & 2.5 & 0.084 & 23 & 2.6 & 0.148 \\
\hline
\end{tabular}

*Significant

Odds Ratio is the ratio of the odds of success for the first procedure (Furlow) to that of the second (von Langenbeck). Values above 1.00 favor the first, whereas values below 1.00 favor the second 
hypernasal speech were 4.2 times the chances of a child in VL-group, while the cul-de-sac measure suggested that the chances of a child in F-group to have absence of hypernasal speech are 11.2 times the chances of a child in VL-group. When only speakers without nasal turbulence were considered, estimated Odds Ratio for all modalities still favored the Furlow procedure with the 4-point scale and the cul-desac measures, suggesting that the chances of a child with RS operated with the Furlow procedure to have absence of hypernasal speech were 8.5 times the chances of a child operated with the von Langenbeck procedure.

\section{Agreement between modalities of assessment}

Table 3 reports the agreement between the four modalities selected for nasality assessment (live 4-point scale, live culde-sac test, listeners' ratings of recorded phrase, and nasalance scores). Kappa statistics revealed scores varying from 0.87 (almost perfect agreement) to 0.32 (reasonable agreement), with a mean score of 0.47 indicating moderate agreement between all modalities. When only the samples without nasal turbulence were considered, Kappa statistics revealed scores varying from 1.00 (perfect agreement) to 0.35 (reasonable agreement), with a mean score of 0.58 also indicating moderate agreement between all modalities.

Table 3. Kappa score indicating agrreement between assessment modalities for all samples $(n=69)$ and also for samples without nasal turbulence $(n=47)$

\begin{tabular}{lcc}
\hline & Kappa $(\mathrm{n}=69)$ & Kappa $(\mathrm{n}=47)$ \\
\hline 4-point scale & & \\
Cul-de-sac & $0.87-$ almost perfect & $1.00-$ perfect \\
Nasometry & $0.32-$ reasonable & $0.35-$ reasonable \\
Listeners & $0.47-$ moderate & $0.62-$ substantial \\
Cul-de-sac & & \\
Nasometry & $0.40-$ reasonable & $0.53-$ moderate \\
Listeners & $0.44-$ moderate & $0.62-$ substantial \\
Nasometry & & \\
Listeners & $0.32-$ reasonable & $0.35-$ reasonable \\
All modalities & $0.47-$ moderate & $0.58-$ moderate \\
\hline
\end{tabular}

\section{DISCUSSION}

Overall findings for this study suggest better nasality outcome for the patients who received the Furlow procedure. While there are some studies that addressed speech after primary palatoplasty for children with RS or that included children with RS in their samples, none compared surgical procedures, or used more than one modality to assess speech nasality, or included an instrumental measure of speech outcome such as nasometry. Most investigations with children with RS involved data retrieved from patient's records and gathered by a single SLP ${ }^{(5,6,10)}$ - different from Timmons et al ${ }^{(8)}$ and the current study, which involved ratings obtained with more than one listener. This study also had the advantadge of involving a single surgeon performing all procedures, allowing for control of inter-surgeon variability.

To report the results of the primary palatoplasty for all 69 patients in this study, the live auditory-peceptual assessment (with the 4-point scale) was selected as the gold standard tool. Hypernasality, as rated using the 4-point scale, was present for $37 \%$ of the children with RS, a finding similar to those of other studies $^{(6,9,11,14)}$ which reported signs of VPI ranging between 36 and $47 \%$, and further compared to Haapanen et al. ${ }^{(7)}$ and Thouvenin et al. ${ }^{(13)}$, who found higher incidence of hypernasality for their patients with RS - 53 and 69\%, respectively.

In this study, patients operated with the Furlow procedure had significantly lower occurrence of hypernasality (26\%) when compared to the patients operated with von Langenbeck procedure (53\%). A clinical trial ${ }^{(4)}$ documenting speech nasality in a group of children with unilateral CLP, without RS, compared speech outcomes between Furlow and von Langenbeck procedures for primary palatoplasty. The authors ${ }^{(4)}$ reported speech nasality using the cul-de-sac test and have shown lower occurrence of hypernasal speech for the children who received the Furlow technique (18\%) compared to those who received the von Langenbeck technique $(29 \%)$. While the finding of the clinical trial ${ }^{(4)}$ was not found statistically significant, it agrees with the current findings, which showed significantly better nasality outcomes for the Furlow group. Even though the current results point towards a trend favoring the Furlow procedure, information regarding width of the cleft prior to primary repair was not available and, since the procedures were not randomized across patients as reported in the clinical trial ${ }^{(4)}$, the bias of the surgeon towards favoring one procedure for wider clefts can not be ruled out in this study. Degree of respiratory obstruction and feeding difficulty have been shown by some authors to have a significant impact in speech results ${ }^{(13)}$; these aspects ${ }^{(4)}$, however, were not documented for the current study and may be another source of bias for babies with RS and should be considered in future investigation.

This study was not designed to evaluate the influence of nasal turbulence in perceptual ratings or nasalance scores, but since the listeners heard the turbulence for 22 samples, the current findings were re-grouped according to presence or absence of nasal turbulence, revealing that mean nasality and nasalance outcomes improved for samples without turbulence. Particularly for nasometric assessment, this finding agreed with previous studies ${ }^{(17,18)}$ that reported on the confounding effect of the turbulent nasal air emission which can increase nasalance score affecting sensitivity and specificity of the instrument.

In spite of the difference between the groups with and without turbulence, the nasometric findings suggested a much higher occurrence of hypernasality than observed with the auditory-perceptual tools. In that regard, one must consider that the nasometer measures aspects of the speech signal different than those perceptually rated by listeners and the acoustic effects of hypernasality are not restricted to the frequency range used by the instrument ${ }^{(19)}$. The use of one short phrase as stimuli ${ }^{(15)}$ and the procedures for perceptual assessment ${ }^{(20)}$ 
may also have a role in these findings, making future studies warranted for this population since other aspects may also explain the higher nasalance scores reported for speakers with RS. Mandibular distraction osteogenesis, for example, is not a procedure used for children with RS at the research institution and none of the children in this study had been submitted to distraction. Children with RS have been reported to present with facial growth differences ${ }^{(21,22)}$, and the presence of micrognathia and posteriorized tongue placement may lead to changes in the configuration of the vocal tract, which may be registered by the nasometer but not identified by the listener. "Muffled" speech resonance is not a well studied deviation of speech nasality and has been referred to as "potato-in-the-mouth" or "cul-de-sac" resonance. While a retrodisplaced mandible and posteriorized tongue can lead to muffled resonance and may mask perception of hypernasality by listeners, the cause and perceptual quality of the "muffled speech phenomenon" is not precisely described in the literature.

Even though it is considered the gold standard for clinical practice, the human ear is unable to perceive all phenomena occurring within the vocal tract during speech production. One study ${ }^{(23)}$, for example, reported on the use of labiallingual double articulations (LLDA) as an abnormal gestural overlap documented in speech of speakers with cleft palate. As explained by the authors ${ }^{(23)}$, these productions occur for bilabial targets and involve lip closure occurring simultaneously with linguo-palatal constriction, which are difficult to be identified perceptually. The authors ${ }^{(23)}$ agreed with Dent et al. ${ }^{(24)}$ that listeners may commonly misclassify LLDA as correct bilabials. Another study ${ }^{(25)}$ reported difficulty among three listeners to identify acoustic differences between glottal stop used for oral target $/ \mathrm{k} /$ and $/ \mathrm{g} /$. The productions of the child with RS and repaired cleft palate showed spectral variability between $/ \mathrm{k} /$ and $/ \mathrm{g} /$, which were not auditorily heard by listeners. The authors ${ }^{(25)}$ suggested that while the child may have used strategies to establish phonetic contrasts in his/her language, these strategies did not have enough magnitude to be perceived by listeners. The clinical experience of the authors of the current study with speech disorders in children with RS suggests that some of these speakers have a strong backing pattern not always identified during auditory-perceptual evaluation but frequently visible during videofluoroscopic assessment. The possibility of speakers with RS using covert contrasts ${ }^{(23)}$ has not been addressed in this study and warrants future investigation.

One study ${ }^{(26)}$ addressed nasality of vowels and consonants in Brazilian Portuguese in normal speakers and speakers with hypernasality. According to the author ${ }^{(26)}$, speakers with hypernasality

present the same tendency as normal speakers for expressing the contrast of nasality in speech, however, they do so in a lower magnitude, which may not be sufficient to be perceived by the listeners (p. 7).

The author ${ }^{(26)}$ interpreted her nasometric findings as suggestive that normal speakers and speakers with hypernasality expressed the contrast of nasality in their speech by means of higher values of nasalance for the nasal sounds, but that the magnitude of this difference is smaller for speakers with hypernasality (p. 7).

Finally, the difference in findings among the four modalities for assessment of nasality in the current study may be due to many aspects of speech production which were not controlled in this study, including the use of different stimuli between live and recorded ratings, the limited length and phonetic context of stimuli for nasometry and listeners' ratings, the presence of covert contrast unidentified by listeners, and also vocal tract characteristics specific to speakers with RS. The findings, therefore, must be interpreted with care and future studies are needed to further investigate the trend towards better nasality results with the Furlow procedure and the relationship among the four different modalities for assessment of nasality.

\section{CONCLUSION}

The purposes of this study were to report outcomes of primary repair of cleft palate in children with RS and the findings suggested lower occurrence of hypernasality for patients in the F-group when compared to the VL-group. Large variability was found among findings as established with four different modalities for assessing speech nasality, with agreement among the different tools varying from almost perfect to reasonable.

*RPO was involved in the elaboration and design of the study, collected and prepared auditory-perceptual data, prepared auditory and instrumental data for comparison and was involved in data analysis and the preparation and revision of this manuscript; ILM was involved in the diagnose of the Robin Sequence of all patients, participated in elaboration and design of the study, was involved in data analysis and the preparation and revision of this manuscript; LS was involved in data analysis and interpretation and revision of this manuscript; TVSB conducted all primary palatoplasties and was involved in data interpretation and revision of this manuscript; JCRD was involved in the design of the study, collected and prepared instrumental data for comparison and was involved in data analysis and the preparation and revision of this manuscript.

\section{REFERENCES}

1. Godbout A, Leclerc JE, Arteau-Gauthier I, Leclerc LD [Internet]. Isolated versus Pierre Robin Sequence cleft palates: are they different? The Cleft Palate-Craniofacial Journal In-Press [cited 2014 Dec 2]. Available from: http://www.cpcjournal.org/doi/pdf/ 10.1597/12-261

2. Marques IL, Prado-Oliveira R, Leirião VHV, Jorge JC, Souza L. Clinica and fiberoptic endoscopic evaluation of swallowing in Robin Sequence treated with nasopharyngeal intubation: the importance of feeding facilitating techniques. Cleft Palate Craniofac J. 2010;47(5):523-9.

3. Collins B, Powitzky R, Robledo C, Rose, Glade R [Internet]. Airway management in Pierre Robin Sequence: patterns of practice. The Cleft Palate-Craniofacial Journal In-Press [cited 2014 Dec 2]. Available from: http://www.cpcjournal.org/doi/pdf/10.1597/12-214

4. Williams WN, Seagle MB, Pegoraro-Krook MI, Souza TV, Garla L, Silva ML, et al. Prospective clinical trial comparing outcome measures between Furlow and von Langenbeck palatoplasties for UCLP. Ann Plast Surg. 2011;66(2):154-63. 
5. Phua YS, de Chalain T. Incidence of oronasal fistulae and velopharyngeal insufficiency after cleft palate repair: and audit of 211 children born between 1990 and 2004. Cleft Palate Craniofac J. 2008; 45(2):172-8.

6. Lehman JA, Fishman JRA, Neiman GS. Treatment of cleft palate associated with Robin Sequence: appraisal of risk factors. Cleft Palate Craniofac J. 1995;32(1):25-9.

7. Haapanen ML, Laitinen S, Paaso M, Ranta R. Quality of speech correlated to craniofacial characteristics of cleft palate patients with the Pierre Robin sequence. Folia Phoniatret Logop. 1996;48(5):215-22.

8. Timmons MJ, Wyatt RA, Murphy T. Speech after repair of isolated cleft palate and cleft lip and palate. Br J Plast Surg. 2001;54(5):377-84.

9. De Buys Roessingh AS, Herzog G, Cherpillod J, Trichet-Zbinden C, Hohlfeld J. Speech prognosis and need of pharyngeal flap for non syndromic vs syndromic Pierre Robin Sequence. J Pediatr Surg. 2008;43(4):668-74.

10. Goudy S, Ingraham C, Canady J. The occurrence of velopharyngeal insufficiency in Pierre Robin Sequence patients. Int J Pediatr Otorhinolaryngol. 2011;75(10):1252-4.

11. Khosla RK, Mabry K, Castiglione CL. Clinical outcomes of the Furlow Z-Plasty for primary cleft palate repair. Cleft Palate Craniofac J. 2008;45(5):501-10.

12. Patel KB, Sullivan SR, Murthy AS, Marrinan E, Mulliken JB. Speech outcome after palatal repair in nonsyndromic versus syndromic Robin sequence. Plast Reconstr Surg. 2012;130(4):577e-84e.

13. Thouvenin B, Djadi-Prat J, Chalouhi C, Pierrot S, Lyonnet S, Couly G, et al. Developmental outcome in Pierre Robin Sequence: a longitudinal and prospective study of a consecutive series of severe phenotypes. Am J Med Genet A. 2013;161A(2):312-9.

14. Stransky C, Basta M, Solot C, Cohen M, Low DW, Larossa D, et al. Do patients with Pierre Robin Sequence have worse outcomes after cleft palate surgery? Ann Plast Surg. 2013;71(3):292-6.

15. Watterson T, Lewis KE, Foley-Homan N. Effect of stimulus length on nasalance scores. Cleft Palate Craniofac J. 1999;36(3):243-7.
16. Trindade IEK, Genaro KF, Dalston RM. Nasalance scores of normal Brazilian Portuguese speakers. Braz J Dysmorphol Speech Hear Disord. 1997;1:23-34.

17. Watterson T, Lewis KE, Deutsch C. Nasalance and nasality in low pressure and high pressure speech. Cleft Palate Craniofac J. 1998;35:293-8.

18. Bastazini SV. Nasalância na presença e ausência da turbulência nasal e da hipernasalidade [dissertação]. Bauru: Universidade de São Paulo; 2008.

19. Keuning KHDM, Wieneke GH, Wijngaarden HA, Dejonckere PH. The correlation between nasalance and a differentiated perceptual rating of speech in Dutch patients with velopharyngeal insufficiency. Cleft Palate Craniofac J. 2002;39(3):277-84.

20. Lohmander A, Willadsen E, Persson C, Henningsson G, Bowden M, Hutters B. Methodology for speech assessment in the Scandcleft Project. An international randomized clinical trial on palatal surgery: experiences from a pilot study. Cleft Palate Craniofac J. 2009;46(4):347-62.

21. Ozawa TO, Lorenzoni DC, Oliveira LGF, Silva-Filho OG. Facial profile evaluation of isolated Pierre Robin Sequence. Cleft Palate Craniofac J. 2012;49(5):546-52.

22. Shen YF, Vargervik K, Oberoi S, Chigurupati R. Facial skeletal morphology in growing children with Pierre Robin Sequence. Cleft Palate Craniofac J. 2012;49(5):553-60.

23. Gibbon FE, Crampin LB. An electropalatographic investigation of middorsum palatal stops in an adult with repaired cleft palate. Cleft Palate Craniofac J. 2001;38(2):96-105.

24. Dent H, Gibbon F, Hardcastle W. Inhibiting an abnormal lingual pattern in cleft palate child using electropalatography. In: Leahy MM, Kallen JL, editors. Interdisciplinary perspectives in speech and language pathology. Dublin: School of Clinical Speech and Language Studies; 1992. p. 211-21.

25. Marino VCC, Berti LC, Lima-Gregio AM. Acoustic characteristics of glottal stop associated to Pierre Robin Sequence: case study. Rev CEFAC. 2013;15(2):466-77.

26. Di Ninno CQMS. O contraste de nasalidade em falantes normais e com fissura palatine: aspectos da produção. [tese]. Belo Horizonte: Universidade Federal de Belo Horizonte; 2008. 